\title{
Association between temperature, humidity and ebolavirus disease outbreaks in Africa, 1976 to 2014
}

S Ng (sophian@princeton.edu) ${ }^{1}$, N E Basta ${ }^{1}$, B J Cowling ${ }^{2}$

1. Department of Ecology and Evolutionary Biology, Princeton University, Princeton, New Jersey, United States

2. School of Public Health, The University of Hong Kong, Hong Kong, China

Citation style for this article:

Ng S, Basta NE, Cowling BJ. Association between temperature, humidity and ebolavirus disease outbreaks in Africa, 1976 to 2014 . Euro Surveill.

2014;19(35): $\mathrm{pii}=20892$. Available online: http://www.eurosurveillance.org/ViewArticle.aspx?Articleld=20892

Ebolavirus disease (EVD) outbreaks have been occurring sporadically in Central Africa since 1976. In 2014, the first outbreak in West Africa was reported in Guinea. Subsequent outbreaks then appeared in Liberia, Sierra Leone and Nigeria. The study of environmental factors underlying EVD epidemiology may provide useful insights into when and where EVD outbreaks are more likely to occur. In this paper, we aimed to investigate the association between climatic factors and onset of EVD outbreaks in humans. Our results suggest lower temperature and higher absolute humidity are associated with EVD outbreak onset in the previous EVD outbreaks in Africa during 1976 to 2014. Potential mechanisms through which climate may have an influence on ebolavirus infection in the natural host, intermediate hosts and humans are discussed. Current and future surveillance efforts should be supported to further understand ebolavirus transmission events between and within species.

\section{Introduction}

Ebolaviruses were first recognised as causing ebolavirus disease (EVD) in humans in outbreaks in South Sudan and the Democratic Republic of the Congo in Central Africa in $1976[1,2]$. The recent EVD outbreak in Guinea in 2014 is the first reported in West Africa [3]. Initial confirmed and probable cases in Liberia and Sierra Leone are reported to have travelled to Guinea [4]. These cases were followed by more extensive outbreaks in the two countries and later on a small number of ebolavirus disease cases were also detected in Nigeria. Genome sequencing analyses revealed that the Zaire ebolavirus causing the outbreak in Guinea was $97 \%$ identical to the Zaire ebolaviruses that had previously caused an outbreak in the Democratic Republic of the Congo and Gabon [5]. Phylogenetic analyses showed the virus isolated in Guinea belongs to a separate clade from previous Zaire ebolaviruses identified in the Democratic Republic of the Congo and Gabon [5]. Other ebolaviruses identified in previous EVD outbreaks in humans in Africa included the Sudan, Côte d'Ivoire and Bundibugyo species [1,6]. Despite the capacity of ebolaviruses to be transmitted between species, including humans, only sporadic outbreaks have been reported and most of them were limited to Central Africa. The spread of the current EVD outbreak outside central African countries to those in western Africa with a high volume of cross-border and international travel have raised concern regarding further spread to other countries within and outside Africa. Despite recent progress in human trials of treatment and vaccines, ebolavirus infections continue to pose a serious public health threat due to the high case fatality risk.

In some previous outbreaks, investigations revealed a clear connection between EVD and contact with the natural reservoir or infected intermediate hosts including bats, chimpanzees and other primates $[1,7]$. The European Centre for Disease Prevention and Control rapid risk assessment concluded direct contact with contaminated secretions, blood, organs and other bodily fluids of living or dead infected persons or animals or with objects heavily contaminated with such fluids have a high potential to lead to transmission [8]. EVD has also arisen as a result of importation of infected animals and laboratory contamination [1] but was not followed by sustained human-to-human transmission.

Seasonal and cyclical patterns of ebolavirus infections have been observed, suggesting seasonal changes in factors such as climate maybe useful predictors of EVD outbreaks $[9,10]$. Examination of these factors may also provide some insight into why EVD had been limited to central parts of Africa in the past and why it has started to appear in West Africa. The objective of this study was to investigate the association between climatic conditions and EVD outbreaks in Africa that occurred between 1976 and 2014, and to discuss potential mechanisms to which climate may have an influence on ebolavirus infection in the natural host, intermediate hosts and humans. 
Characteristics of human ebolavirus disease outbreaks in five African countries included in analyses of the effect of climatic conditions, 1976-2014

\begin{tabular}{|c|c|c|c|c|c|c|c|}
\hline Country & Area & $\begin{array}{l}\text { Onset of first } \\
\text { outbreak }\end{array}$ & $\begin{array}{l}\text { End of last } \\
\text { outbreak }\end{array}$ & $\begin{array}{c}\text { Years of climate } \\
\text { data analysed }\end{array}$ & $\begin{array}{l}\text { Ebolavirus } \\
\text { species }\end{array}$ & $\begin{array}{c}\text { Mean } \\
\text { temperature } \\
\text { in }{ }^{\circ} \mathrm{C}(\mathrm{SD})\end{array}$ & $\begin{array}{c}\text { Mean absolute } \\
\text { humidity } \\
\text { in } \mathrm{kg} / \mathrm{m}^{3} \text { (SD) }\end{array}$ \\
\hline \multirow{3}{*}{ Guinea } & Guékédou & Jan 2014 & Ongoing & $2013-2014^{a}$ & Zaire & $25.53(0.96)$ & $16.50(1.55)$ \\
\hline & Macenta & Jan 2014 & Ongoing & $2013-2014^{a}$ & Zaire & $24.79(0.94)$ & $15.22(1.50)$ \\
\hline & Kissidougou & Jan 2014 & Ongoing & $2013-2014^{a}$ & Zaire & $25.31(1.08)$ & $15.70(2.04)$ \\
\hline \multirow{4}{*}{ Gabon } & Andock & Dec 1994 & Feb 1995 & $1993-1995$ & Zaire & $26.50(1.08)$ & $20.10(1.27)$ \\
\hline & Mayibout II & Jan 1996 & Apr 1996 & $1995-1996$ & Zaire & $24.80(0.94)$ & $18.38(0.62)$ \\
\hline & Booué & Jul 1996 & Jan 1997 & $1995-1997$ & Zaire & $26.37(0.93)$ & $19.76(0.88)$ \\
\hline & Ogooué-Ivindo & Oct 2001 & Mar 2002 & $2000-2002$ & Zaire & $25.38(1.06)$ & $18.86(0.74)$ \\
\hline \multirow{8}{*}{$\begin{array}{l}\text { Democratic } \\
\text { Republic of the } \\
\text { Congo }\end{array}$} & Bumba & Sep 1976 & Oct 1976 & $1975-1976$ & Zaire & $24.94(0.63)$ & $18.17(0.35)$ \\
\hline & Tandala & Jun 1977 & Jun 1977 & $1976-1977$ & Zaire & $25.50(0.70)$ & $18.67(0.57)$ \\
\hline & Kikwit & Jan 1995 & Jul 1995 & $1994-1995$ & Zaire & $25.18(0.57)$ & $17.55(1.54)$ \\
\hline & Cuvette-Ouest & Dec 2002 & Dec 2003 & $2001-2003$ & Zaire & $24.93(0.89)$ & $18.49(0.74)$ \\
\hline & Kasai Occidental & May 2007 & Oct 2007 & $2006-2007$ & Zaire & $24.84(0.53)$ & $18.21(0.80)$ \\
\hline & Mweka & Nov 2008 & Jan 2009 & $2007-2009$ & Zaire & $24.81(0.55)$ & $18.21(0.80)$ \\
\hline & Luebo & Nov 2008 & Jan 2009 & 2007-2009 & Zaire & $24.44(0.61)$ & $17.75(0.96)$ \\
\hline & Isiro & Aug 2012 & Oct 2012 & $2011-2012$ & Zaire & $24.32(1.36)$ & $18.45(0.97)$ \\
\hline \multirow{2}{*}{ South Sudan } & Nzara & Jun 1976 & Oct 1979 & $1975-1979$ & Sudan & $24.27(0.98)$ & $15.95(1.57)$ \\
\hline & Yambio & Apr 2004 & Jun 2004 & $2003-2004$ & Sudan & $26.05(1.18)$ & $17.51(1.73)$ \\
\hline \multirow{6}{*}{ Uganda } & Gulu & Aug 2000 & Jan 2001 & $1999-2001$ & Sudan & $24.69(1.26)$ & $15.27(1.59)$ \\
\hline & Masindi & Aug 2000 & Dec 2000 & $1999-2000$ & Sudan & $23.17(0.87)$ & $15.15(0.87)$ \\
\hline & Mbarara & Aug 2000 & Jan 2001 & $1999-2001$ & Sudan & $19.79(0.66)$ & $13.00(0.75)$ \\
\hline & Bundibugyo & Aug 2007 & Dec 2007 & $2006-2007$ & Bundibugyo & $18.76(1.16)$ & $13.02(0.81)$ \\
\hline & Luwero & May 2011 & Nov 2012 & $2010-2012$ & Sudan & $23.27(1.26)$ & $15.54(0.95)$ \\
\hline & Kibaale & Jul 2012 & Aug 2012 & $2011-2012$ & Sudan & 25.19 (0.99) & $16.20(1.82)$ \\
\hline
\end{tabular}

SD: standard deviation.

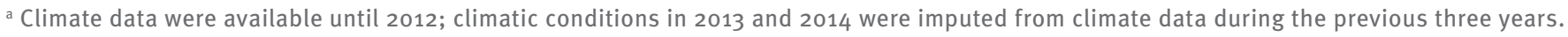

\section{Methods}

\section{Sources of data}

A total of 28 reported EVD outbreaks in Africa were identified from records and references listed on the United States Centers for Disease Control and Prevention website [1]. These outbreaks have occurred in the Democratic Republic of the Congo, Congo, South Sudan, Gabon and Uganda since 1976, and recently in Guinea. Because this study is focused on emergence and local transmission of the viruses, two reports involving a medical professional who treated a case from an outbreak in Gabon and later travelled immediately to South Africa in 1996, and a scientist who performed an autopsy of a wild chimpanzee in Côte d'Ivoire in 1994 were excluded.

The onset of an outbreak is defined by the date of the first reported probable or laboratory-confirmed case. Climate data, including ambient temperature, vapour pressure and dew point, at the outbreak locations were obtained from the Climate Research Unit, University of
East Anglia, United Kingdom [11]. Absolute humidity was calculated using the conversion formula published by the National Aeronautics and Space Administration [12].

\section{Statistical methods}

A distributed lag non-linear model (DLNM) developed by Gasparrini et al. [13] was used in our analyses to examine the association between climatic factors and EVD outbreaks [7]. DLNM was used since it allows for a non-linear exposure-response relationship and provides flexibility in modelling the time structure of the relationship. The time structure is specified so that the log odds of an EVD outbreak can vary between each lag period following exposure of humans and intermediate host and natural host populations to certain climatic conditions at each outbreak area.

An earlier report of a detailed EVD outbreak investigation suggested exposure of the first cases to infected bats might precede detected outbreaks in humans by three months [7]. Lagged effects of one month, two months and three months were considered when our 


\section{FIGURE 1}

Geographical distribution of human ebolavirus disease outbreaks included in analyses of monthly temperature and absolute humidity, 1976-2014

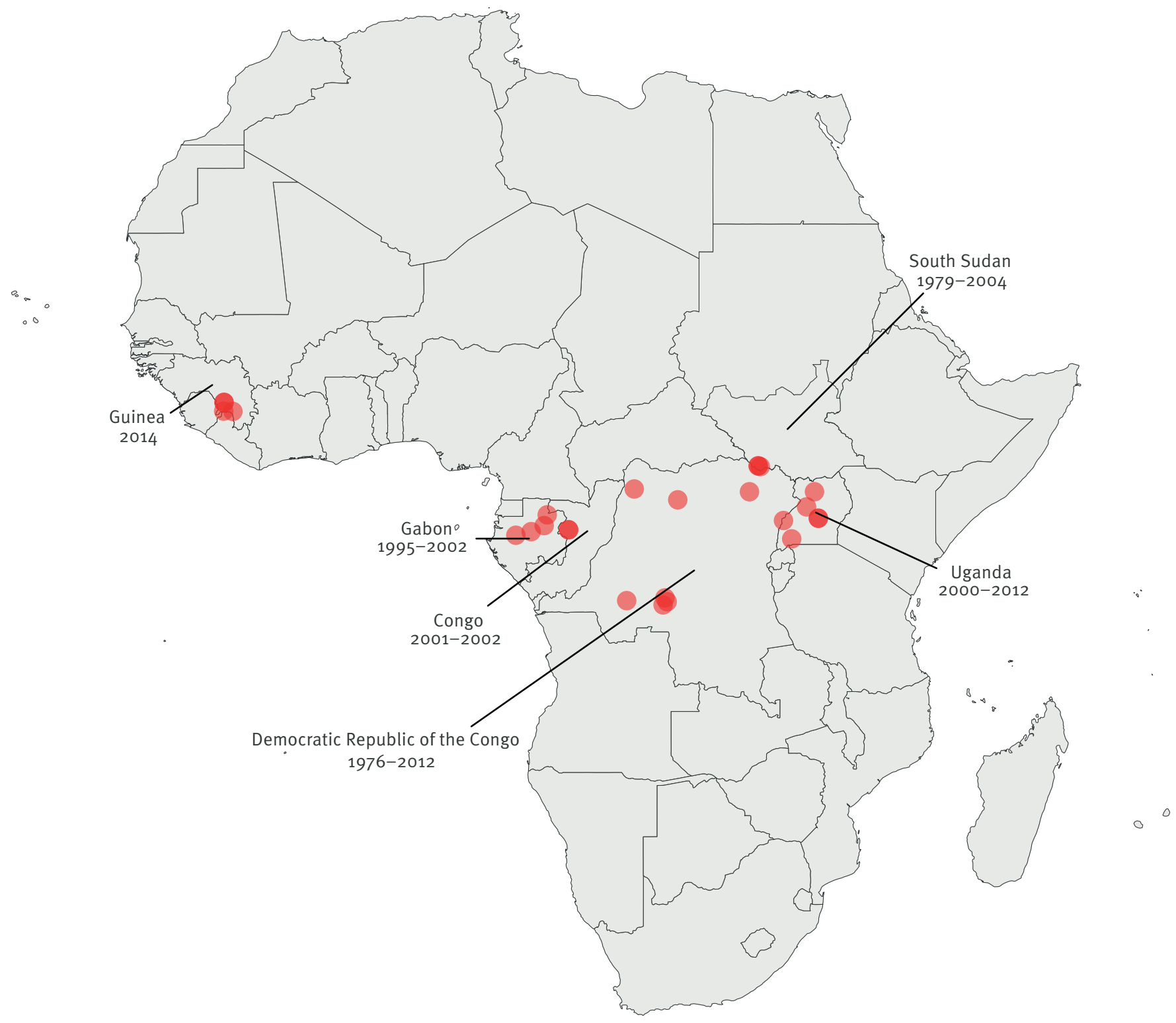

The red circles represent the outbreak areas.

models were fitted. The relationship between exposure variables (monthly temperature and absolute humidity) and the log odds of response (onset of an EVD outbreak in humans) were specified using first (linear) and second (quadratic) degree orthogonal polynomials in binomial regression models. Likewise, zeroth (uniform), first (linear) and second (quadratic) degree orthogonal polynomials were used to specify the time structure of the exposure-response relationship.

Climate data were available until 2012 and the monthly temperature and absolute humidity in 2013 and 2014 were imputed using the mean same month observations during the previous three years. Climate data for
Gabon was used for one outbreak that occurred at the border between Congo and Gabon.

Annual climate data from the year before the first outbreak to the year of the last outbreak at each outbreak area were analysed. Odds ratios of EVD outbreaks associated with deviation from mean climatic conditions over these years were calculated. The standardised monthly temperature and absolute humidity were visualised and variance inflation factors were calculated to inspect for multicollinearity between the two explanatory variables. The standardisation was carried out within each of the smallest geographical jurisdictions described in the outbreak reports. Separate models 
Standardised monthly temperature and absolute humidity in five African countries with human ebolavirus disease outbreaks ${ }^{\mathrm{a}}, 1976-2014$
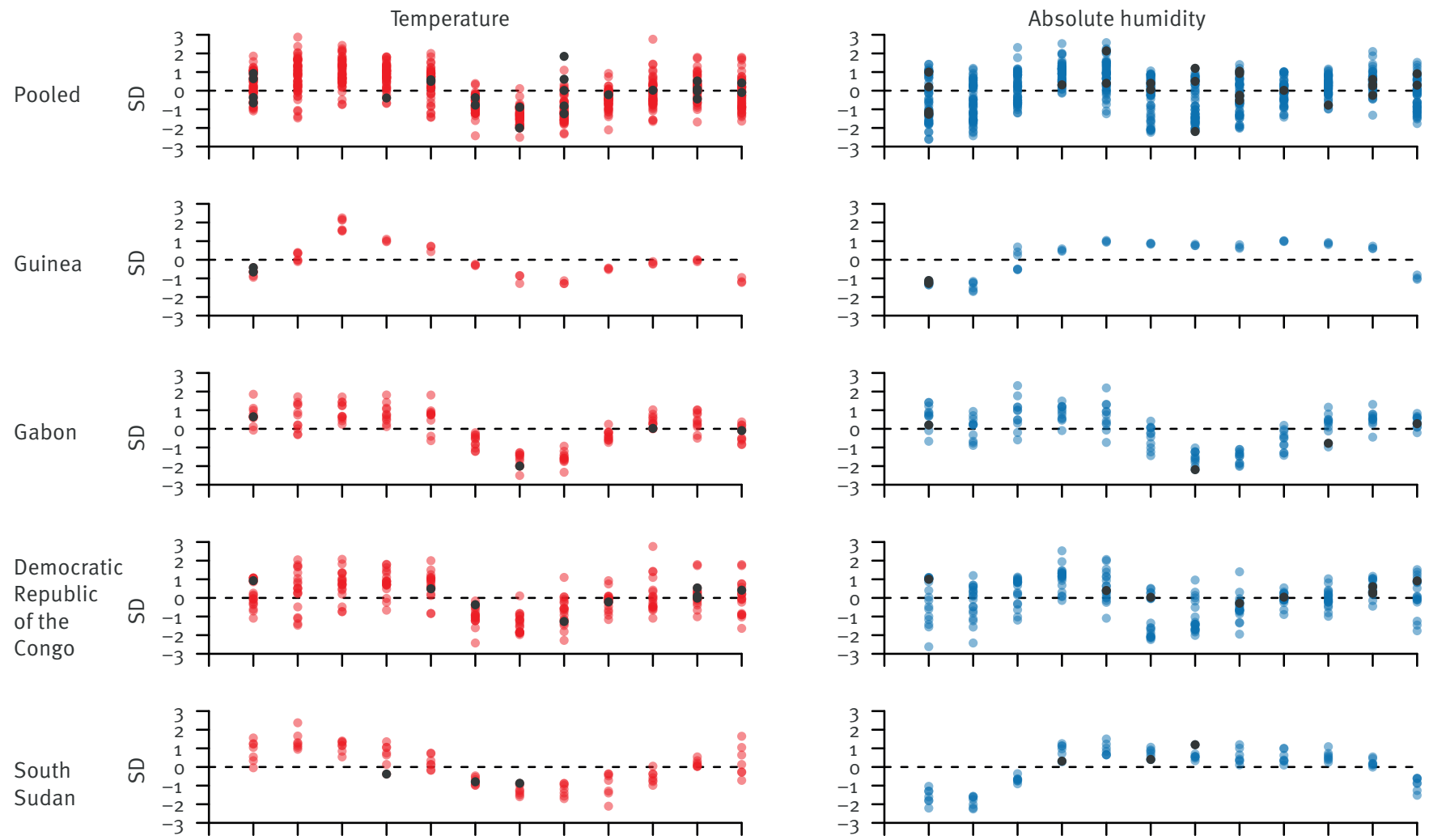

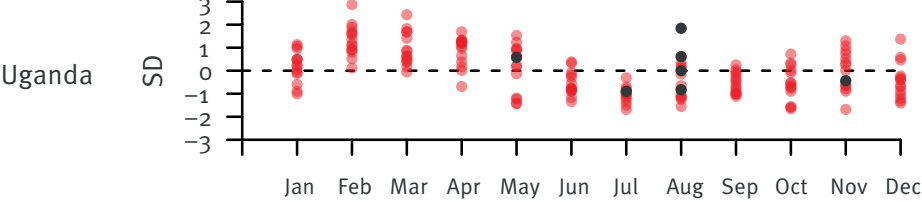

Month

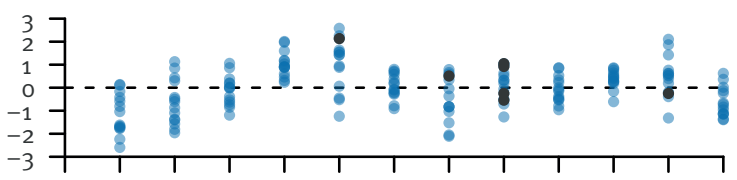

Jan Feb Mar Apr May Jun Jul Aug Sep Oct Nov Dec Month

SD: standard deviation.

Standardised monthly temperature (red circles) and absolute humidity (blue circles) are shown.

The observations during onset months of ebolavirus disease outbreaks are highlighted as black circles. The mean and standard deviation of temperature and absolute humidity and the years of climate data included in the analyses for each outbreak area can be found in Table 1.

a Democratic Republic of the Congo, Gabon, Guinea, South Sudan and Uganda. An outbreak occurring at the border of the Republic of Congo and Gabon was included here as an outbreak in Gabon.

were used for temperature and absolute humidity when evidence of multicollinearity was observed.

General estimating equations (GEE) [14] were used to adjust for correlations between multiple observations within the smallest geographical jurisdiction described in the outbreak reports. Both pooled and stratified analyses were performed for the five outbreak countries: the Democratic Republic of the Congo, Gabon, Guinea, South Sudan and Uganda. Quasilikelihood under the independence model criterion (QIC) is a modification of Akaike's information criterion (AIC) for models using GEE [15]. All model specifications were evaluated using QIC and the final models with the lowest QIC were selected.

\section{Results}

The geographical distribution of EVD outbreaks in the Democratic Republic of the Congo, Gabon, Guinea, South Sudan and Uganda is shown in Figure 1. The mean and standard deviation of monthly temperature and absolute humidity, causative ebolavirus species and outbreak period in each outbreak area are listed in Table $1[1,6,16]$. In Guinea, the mean temperature was rather similar to that of other areas with outbreaks of Zaire ebolavirus disease (in the Democratic Republic of the Congo and Gabon), while the mean absolute 
Correlation between standardised mean monthly temperature and absolute humidity in five African countries with human ebolavirus disease outbreaks ${ }^{a}, 1976-2014$
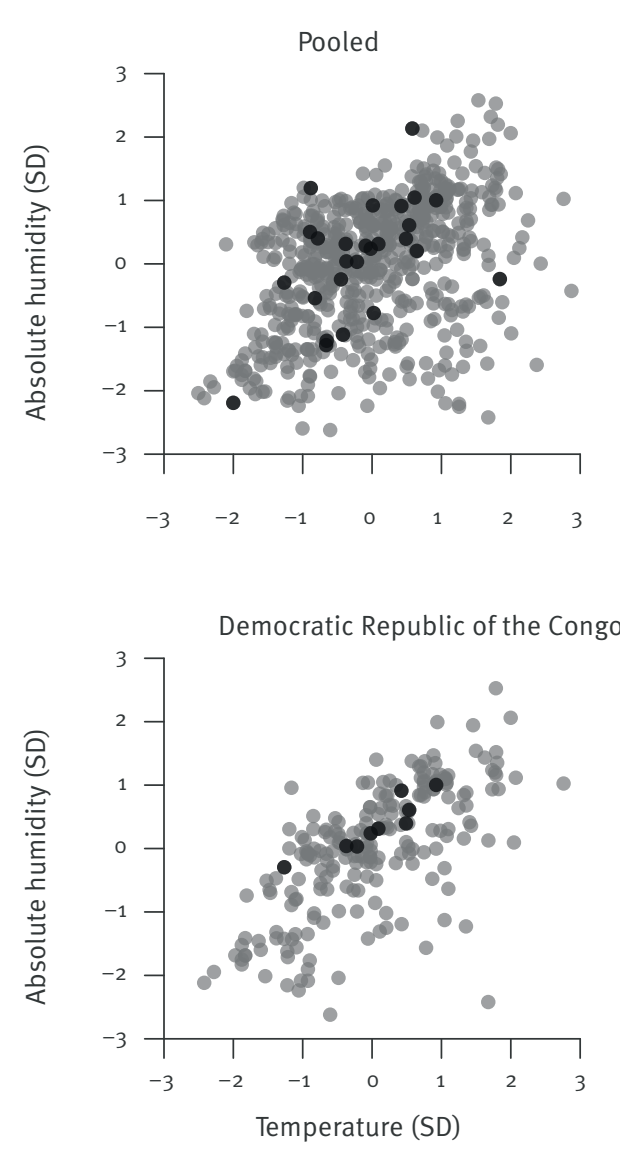
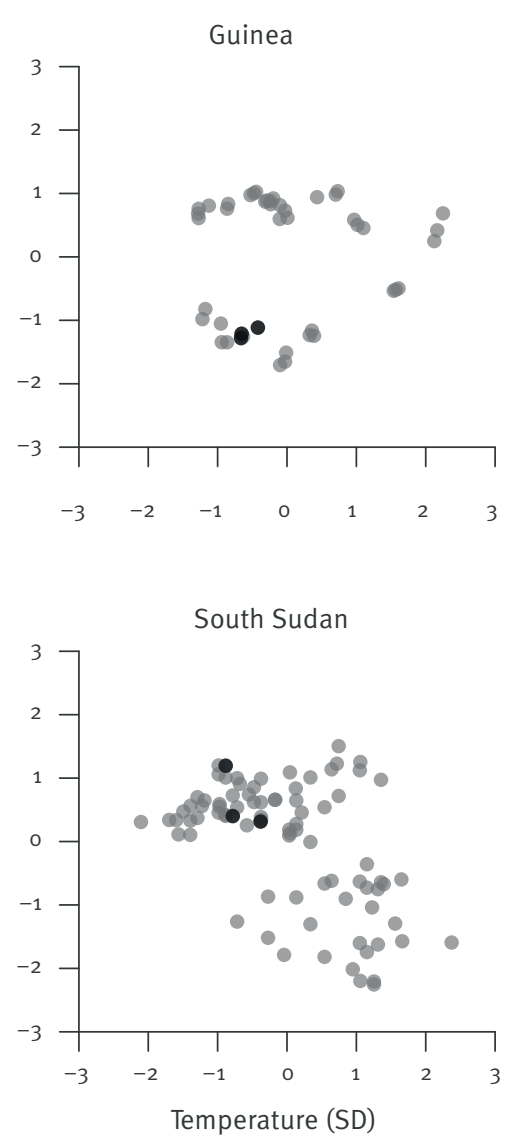
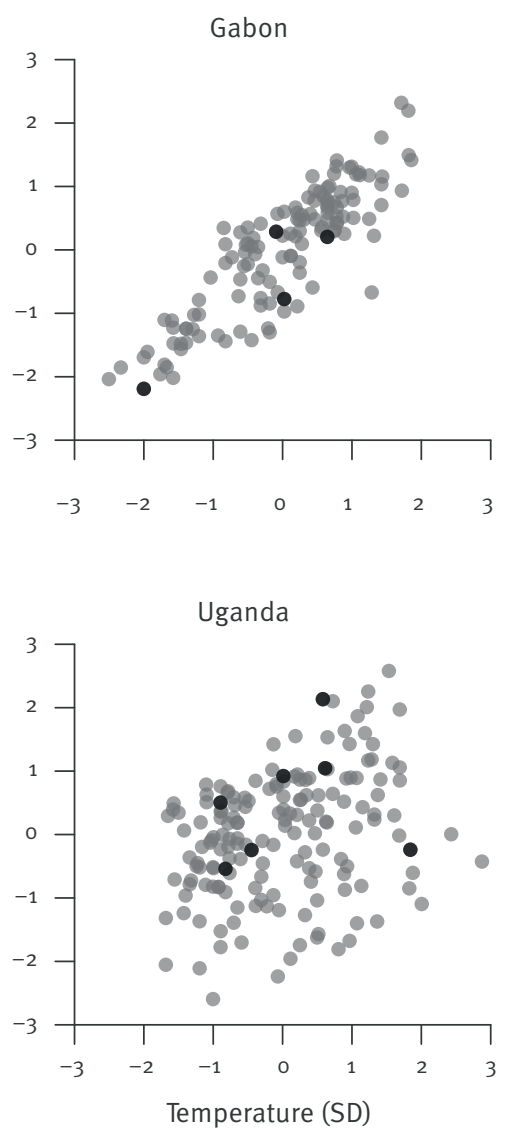

SD: standard deviation.

The correlation between standardised mean monthly temperature and absolute humidity is shown as grey circles. The observations during onset months of ebolavirus disease outbreaks are highlighted as black circles. The years of climate data included in the analyses for each outbreak area can be found in Table 1.

a Democratic Republic of the Congo, Gabon, Guinea, South Sudan and Uganda. An outbreak occurring at the border of the Republic of Congo and Gabon was included here as an outbreak in Gabon.

humidity was lower, as in areas where previous outbreaks of Sudan ebolavirus disease occurred (Sudan and Uganda) [1]. Standardised monthly temperature and absolute humidity in the five countries analysed are shown in Figure 2. Consistent patterns in annual variation of temperature were observed across the five countries: June to August was generally cooler than the mean with February to April being the warmer months. The annual pattern of absolute humidity was, however, less consistent between countries. While the absolute humidity remained above the mean from April to November in Guinea and South Sudan, only March and April were more humid in the other three countries. In Gabon, July and August were noticeably drier, but this was not seen elsewhere. Since temperature and absolute humidity in the Democratic Republic of the Congo and Gabon were highly positively correlated (Figure 3), separate models were used in analysing their correlation with EVD outbreak onset. The variance inflation factors were low in Guinea, South Sudan, Uganda and in the pooled analyses, therefore temperature and absolute humidity were included as covariates in the same models.

In the pooled analysis, the best-fitting model specified a uniform exposure-response relationship across the two months' lag period for temperature and the three months' lag period for absolute humidity (Table 2). Lower temperature and higher humidity (standard deviation) were found to log-linearly associate with increased risk of human EVD outbreak onset during each month in the lag periods. The estimated cumulative log odds ratio of human EVD outbreak onset at each month following exposure of humans and intermediate host and natural host populations to certain climatic conditions are shown in Figure 4. These associations were shown to be statistically significant across the entire lag period (Tables 3 and 4). Analyses stratified by country were underpowered and analyses only including areas with Zaire ebolavirus outbreaks 
Model specifications of the best-fitting models selected based on quasilikelihood under the independence model criterion, in five African countries with human ebolavirus outbreaks, 1976-2014

\begin{tabular}{|c|c|c|c|c|c|c|}
\hline $\begin{array}{l}\text { Country and outbreaks } \\
\text { by ebolavirus species }\end{array}$ & $\begin{array}{l}\text { Lag period } \\
\text { following } \\
\text { exposure } \\
\text { temperature } \\
\text { (in months) }\end{array}$ & $\begin{array}{l}\text { Lag period } \\
\text { following } \\
\text { exposure } \\
\text { to absolute } \\
\text { humidity (in } \\
\text { months) }\end{array}$ & $\begin{array}{l}\text { Degree of orthogonal } \\
\text { polynomial used to } \\
\text { specify the relationship } \\
\text { between temperature } \\
\text { and the log odds of EVD } \\
\text { outbreak }\end{array}$ & $\begin{array}{l}\text { Degree of orthogonal } \\
\text { polynomial used to } \\
\text { specify the relationship } \\
\text { between absolute } \\
\text { humidity and the log } \\
\text { odds of EVD outbreak }\end{array}$ & $\begin{array}{l}\text { How odds ratio } \\
\text { vary across } \\
\text { lag period } \\
\text { following } \\
\text { exposurea to } \\
\text { temperature }\end{array}$ & $\begin{array}{l}\text { How odds ratio } \\
\text { vary across } \\
\text { lag period } \\
\text { following } \\
\text { exposurea } \\
\text { to absolute } \\
\text { humidity }\end{array}$ \\
\hline \multicolumn{7}{|l|}{ Country } \\
\hline Pooled & 2 & 3 & $1 \mathrm{st}$ & $1 \mathrm{st}$ & Uniform & Uniform \\
\hline Guineab $^{b}$ & - & - & - & - & - & - \\
\hline Gabon $^{c}$ & 2 & NA & $1 \mathrm{st}$ & NA & Uniform & NA \\
\hline Gabon $^{\mathrm{d}}$ & NA & 2 & NA & $1 \mathrm{st}$ & NA & Uniform \\
\hline $\begin{array}{l}\text { Democratic Republic of } \\
\text { the Congoc }\end{array}$ & 2 & NA & $1 \mathrm{st}$ & NA & Uniform & NA \\
\hline $\begin{array}{l}\text { Democratic Republic of } \\
\text { the Congo }\end{array}$ & NA & 1 & NA & 2nd & NA & Uniform \\
\hline South Sudan & 1 & 1 & $1 \mathrm{st}$ & $1 \mathrm{st}$ & Uniform & Uniform \\
\hline Uganda & 2 & 3 & $1 \mathrm{st}$ & 2nd & Uniform & Uniform \\
\hline \multicolumn{7}{|l|}{ Ebolavirus species } \\
\hline Zaire species outbreaks & 2 & 3 & $1 \mathrm{st}$ & $1 \mathrm{st}$ & Uniform & Uniform \\
\hline Sudan species outbreaks & 2 & 3 & $1 \mathrm{st}$ & $1 \mathrm{st}$ & Uniform & Uniform \\
\hline $\begin{array}{l}\text { Bundibugyo species } \\
\text { outbreaks }\end{array}$ & - & - & - & - & - & - \\
\hline
\end{tabular}

EVD: ebolavirus disease; NA: not applicable.

a Exposure of humans and intermediate host and natural host populations.

b The analysis was not performed due to insufficient number of outbreaks.

c Model including temperature as explanatory variable.

${ }^{\mathrm{d}}$ Model including absolute humidity as explanatory variable.

produced consistent conclusions (Figure 5). Stratified analyses for Sudan and Bundibugyo species were underpowered. The specifications of the best-fitting stratified models can be found in Table 2 .

\section{Discussion}

Our analyses of human EVD outbreaks in Africa suggest that the onset of these outbreaks was associated with conditions with higher absolute humidity and lower temperature when their time-lagged effects are taken into account. This is one of the first studies to examine the association between climatic factors and EVD outbreaks in humans. Our findings are consistent with the prediction of previous ecological niche models that ebolaviruses are more likely to be distributed in areas of humid Afrotropic rainforests where the temperature is moderate [17]. Previous EVD outbreaks in humans have been observed in both dry and wet seasons $[9,10,18-20]$. This is consistent with our analysis (Figure 2), which shows that when the time-lagged effect of environmental exposure is not considered, EVD outbreaks do not have a clear association with temperature and humidity.

On the basis of knowledge of ebola-related viruses, there has been speculation that plants, arthopods, bats and many other animals could be the natural host for ebolaviruses [21]. However, to date, evidence of potential ebolavirus persistence has only been found in bats [22]. Further animal virological studies are required to identify and verify all natural host species for ebolaviruses. Although seasonal patterns of ebolavirus infections among bats and other potential natural hosts have not been fully characterised, seroprevalence studies in bats have found the highest rates of seropositivity among adults and pregnant females [23]. This finding leads to the postulation that fighting and mating among bats may be associated with ebolavirus transmission [23]. These behaviours have been documented to be most frequent during rainy or wet seasons [24]: this may partly explain how climatic factors are associated with ebolavirus infection risk among bats, one of the potential natural hosts.

Viral persistence studies in EVD patients have found the virus to be more persistent in semen than in other bodily fluids and fomites [25]. Ebolavirus was found to remain detectable in semen for up to 91 days [26]. This finding highlights the relative importance of sexual transmission, if virus shedding in bats follows a similar pattern. 


\section{FIGURE 4}

Estimated cumulative odds ratios of onset of human ebolavirus disease outbreaks at each month following exposure of humans and intermediate host and natural host populations to certain climatic conditions in five African countries with human ebolavirus disease outbreaks ${ }^{\mathrm{a}}, 1976-2014$
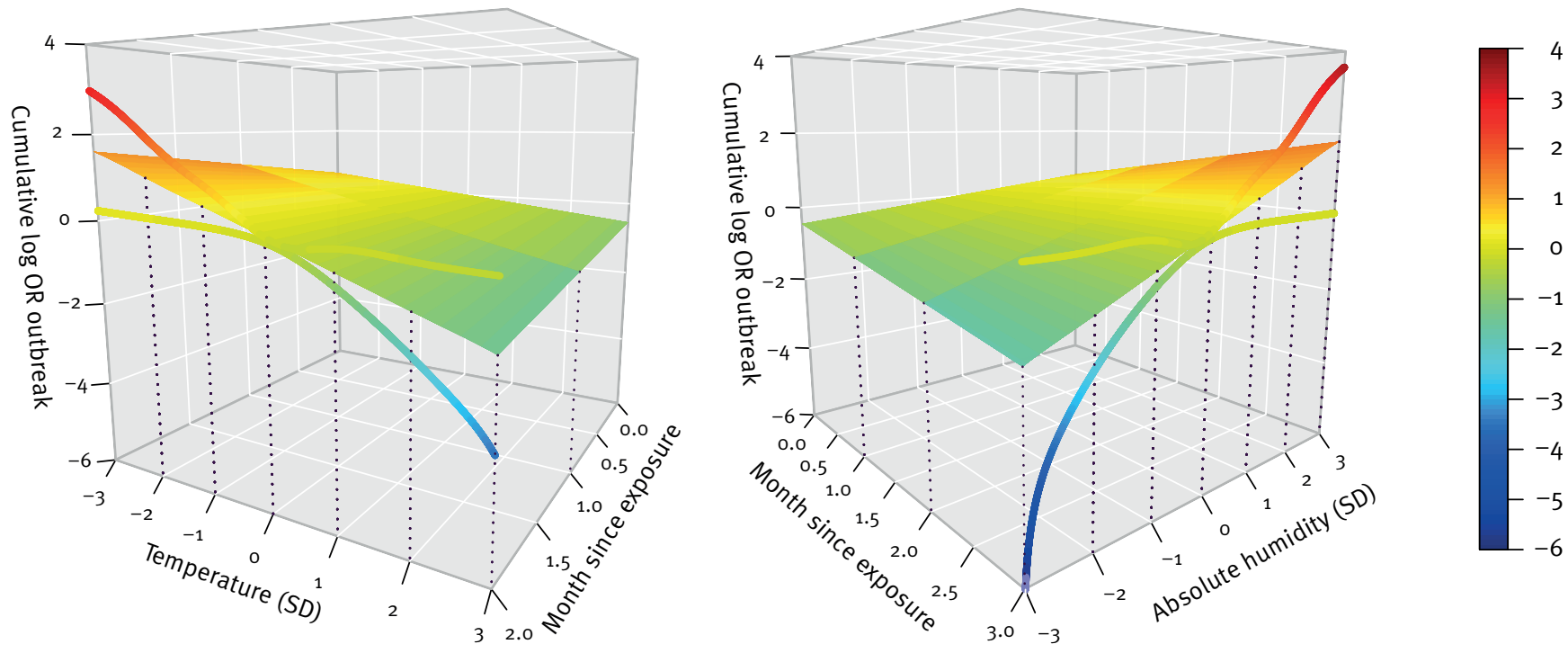

$\mathrm{Cl}$ : confidence interval; OR: cumulative odds ratio; SD: standard deviation.

The lag period was two months for the effect of temperature and three months for absolute humidity. The OR was calculated with reference to ebolavirus disease outbreak onset risk at mean temperature/absolute humidity conditions. The $95 \%$ Cls for the estimated cumulative log $O R$ at the end of the lag period are shown as the two lines enclosing the surface that shows the cumulative log OR. The mean and standard deviation of temperature and absolute humidity, and the years of climate data included in the analyses for each outbreak area can be found in Table 1. Numerical values for all ORs and $95 \%$ Cls can be found in Tables 3 and 4.

a Democratic Republic of the Congo, Gabon, Guinea, South Sudan and Uganda. An outbreak occurring at the border of the Republic of Congo and Gabon was included here as an outbreak in Gabon.

\section{TABLE 3}

Estimated cumulative odds ratio of onset of human ebolavirus disease outbreaks at each month following exposure to temperature conditions ${ }^{\mathrm{a}}$, 1976-2014

\begin{tabular}{|l|c|c|c|}
\hline \multirow{2}{*}{ Temperature (SD) } & Same month & First month & OR $(95 \% \mathrm{Cl})$ \\
\hline-3 & OR $(95 \% \mathrm{Cl})$ & $2.93(1.17-7.29)$ & $5.00(1.27-19.68)$ \\
\hline-2 & $1.71(1.08-2.70)$ & $2.05(1.11-3.76)$ & $2.93(1.17-7.29)$ \\
\hline-1 & $1.43(1.06-1.94)$ & $1.43(1.06-1.94)$ & $1.71(1.08-2.70)$ \\
\hline 0 & $1.20(1.03-1.39)$ & $1.00(1.00-1.00)$ & $1.00(1.00-1.00)$ \\
\hline 1 & $1.00(1.00-1.00)$ & $0.70(0.52-0.95)$ & $0.58(0.37-0.92)$ \\
\hline 2 & $0.84(0.72-0.97)$ & $0.49(0.27-0.90)$ & $0.34(0.14-0.85)$ \\
\hline 3 & $0.70(0.52-0.95)$ & $0.34(0.14-0.85)$ & $0.20(0.05-0.79)$ \\
\hline
\end{tabular}

$\mathrm{Cl}$ : confidence interval; OR: cumulative odds ratio; SD: standard deviation.

a Estimated from the best-fitting model for the pooled analyses of outbreaks caused by Zaire, Sudan and Bundibugyo ebolaviruses in Guinea, Gabon, Democratic Republic of the Congo, South Sudan and Uganda. The outbreak areas and time period included in the analyses are described in Table 1. The best-fitting model included two months as the duration of the lag effect.

Seasonal migration of fruit bats may result in increased contact with humans and other animals [10]. An outbreak investigation in the Democratic Republic of the Congo in 2007 linked the first human case to migratory bats that stayed in the area during the migratory season [7]. Further investigation should be carried out to study whether disruption/change in migratory route or virus acquisition in other bat species with a different geographical range would explain the first outbreak in West Africa. Bats host many viruses that are highly pathogenic in other mammals [27]. It has been hypothesised that flight activities maintain a high body temperature and metabolic rate, which may mimic the effect of a febrile immune response in limiting virulence of a virus that may otherwise be highly pathogenic $[27,28]$. Seasonal environmental and behavioural 
TABLE 4

Estimated cumulative odds ratios of onset of human ebolavirus disease outbreaks at each month following exposure to absolute humidity conditions ${ }^{\mathrm{a}}$, 1976-2014

\begin{tabular}{|c|c|c|c|c|}
\hline \multirow{2}{*}{ Absolute humidity (SD) } & Same month & First month & Second month & Third month \\
\hline & OR $(95 \% \mathrm{Cl})$ & OR $(95 \% \mathrm{CI})$ & OR $(95 \% \mathrm{Cl})$ & OR $(95 \% \mathrm{Cl})$ \\
\hline-3 & $0.64(0.40-1.00)$ & $0.40(0.16-1.00)$ & $0.26(0.07-1.00)$ & $0.16(0.03-1.00)$ \\
\hline-2 & $0.74(0.55-1.00)$ & $0.55(0.30-1.00)$ & $0.40(0.16-1.00)$ & $0.30(0.09-1.00)$ \\
\hline-1 & $0.86(0.74-1.00)$ & $0.74(0.55-1.00)$ & $0.64(0.40-1.00)$ & $0.55(0.30-1.00)$ \\
\hline 0 & $1.00(1.00-1.00)$ & $1.00(1.00-1.00)$ & $1.00(1.00-1.00)$ & $1.00(1.00-1.00)$ \\
\hline 1 & $1.16(1.00-1.35)$ & $1.35(1.00-1.83)$ & $1.57(1.00-2.47)$ & $1.83(1.00-3.34)$ \\
\hline 2 & $1.35(1.00-1.83)$ & $1.83(1.00-3.34)$ & $2.47(1.00-6.11)$ & $3.34(1.00-11.18)$ \\
\hline 3 & $1.57(1.00-2.47)$ & $2.47(1.00-6.11)$ & $3.88(1.00-15.11)$ & $6.10(1.00-37.37)$ \\
\hline
\end{tabular}

$\mathrm{Cl}$ : confidence interval; OR: cumulative odds ratio; SD: standard deviation.

a Estimated from the best-fitting model for the pooled analyses of outbreaks caused by Zaire, Sudan and Bundibugyo ebolaviruses in Guinea, Gabon, Democratic Republic of the Congo, South Sudan and Uganda. The outbreak areas and time period included in the analyses are described in Table 1. The best-fitting model included three months as the duration of the lag effect.

\section{FIGURE 5}

Estimated cumulative odds ratios of onset of human Zaire ebolavirus disease outbreaks at each month following exposure of humans and intermediate host and natural host populations to certain climatic conditions in three African countries with human Zaire ebolavirus disease outbreaks ${ }^{\mathrm{a}}$, 1976-2014
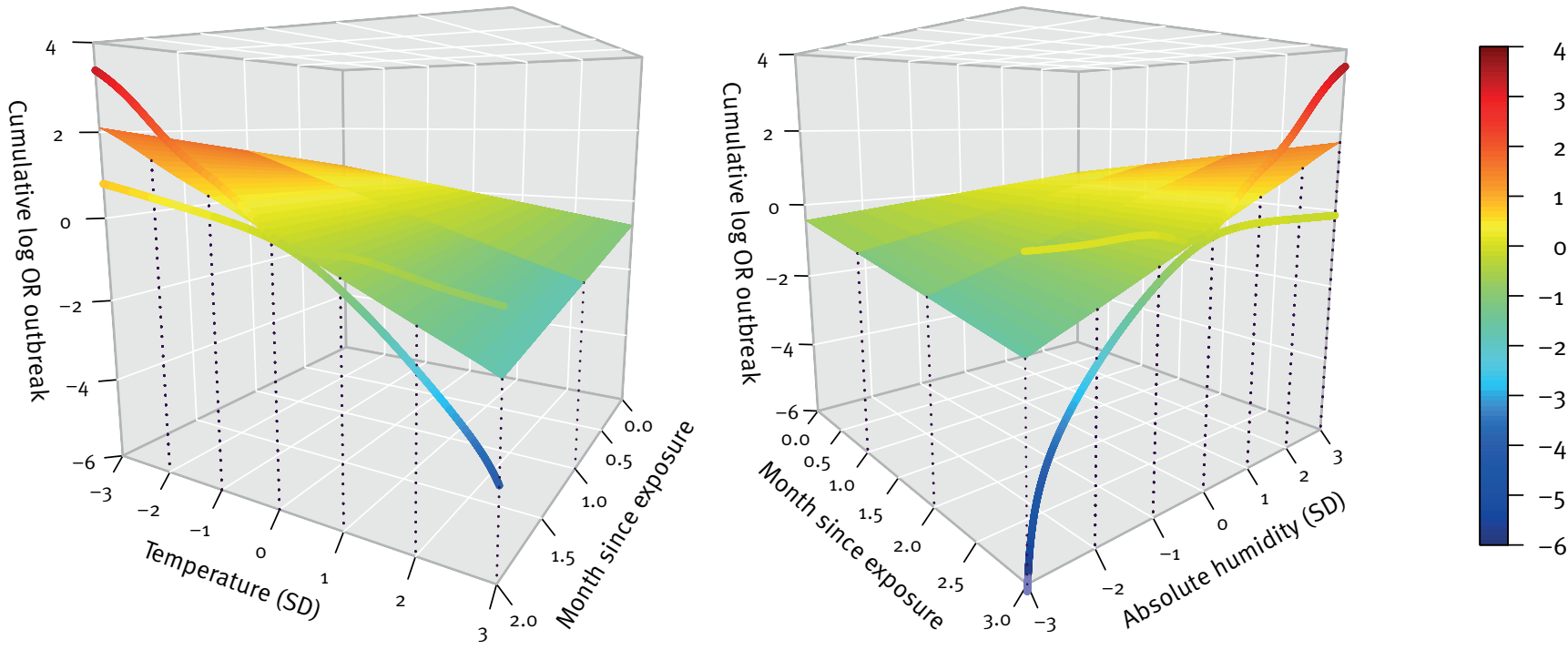

$\mathrm{Cl}$ : confidence interval; OR: cumulative odds ratio; SD: standard deviation.

The lag period was two months for the effect of temperature and three months for absolute humidity. The OR was calculated with reference to Zaire ebolavirus disease outbreak onset risk at mean temperature/absolute humidity conditions. The $95 \% \mathrm{Cls}$ for the estimated cumulative $\log$ OR at the end of the lag period are shown as the two lines enclosing the surface that shows the cumulative log OR. The mean and standard deviation of temperature and absolute humidity, and the years of climate data included in the analyses for each outbreak area can be found in Table 1. Numerical values for all ORs and $95 \%$ Cls can be found in Tables 3 and 4 .

a Democratic Republic of the Congo, Gabon, Guinea, South Sudan and Uganda. An outbreak occurring at the border of the Republic of Congo and Gabon was included here as an outbreak in Gabon.

factors such as long migratory flight may influence body temperature and metabolic rate in bats. This may result in altered susceptibility to and severity of ebolavirus infection. Reduction in susceptibility and severity may have bidirectional effects on ebolavirus transmission dynamics. While less severe infections may allow infected bats to remain active in transmitting the virus, reduction in susceptibility may reduce the overall infection rate among the bat population.
Peaks in mortality due to EVD in chimpanzees, gorillas and duikers (a type of antelope) were observed to coincide with some of the previous human EVD outbreaks [29]. EVD outbreaks in non-human primates have mostly been reported to occur at the end of rainy seasons $[10,30,31]$ : however, it has been unclear whether this was due to earlier humid conditions or current dry conditions. As in bats, the behaviour of non-human primates and their exposure to bats may vary with the 
season. A study of chimpanzees in Côte d'Ivoire found that they made a higher number of kills per day when hunting in the wet seasons [32]. This may lead to a sudden increase in consumption or contact with prey that is a natural reservoir of ebolaviruses. Furthermore, increased social mixing during wet seasons may also facilitate transmission of ebolaviruses among chimpanzees [24]. Similarly, human-to-human and humanto-animal contact patterns may have a seasonal effect on the risk of an EVD outbreak in humans.

While natural hosts such as bats can serve as a common source of cross-species transmission for humans and other primates, non-human primates can act as intermediate hosts in zoonotic events that result in human infections. Therefore, the time frame of the spillover effect of environmental exposure in the natural hosts may depend on the transmission chain of the zoonotic events and how these events are associated with climate. Environmental exposure may also have transient, immediate effects on the susceptibility to and severity of ebolavirus infection among natural hosts, intermediate hosts and humans. Previous experimental studies have found human exposure to low temperature may trigger changes in the immune response [33-36]. If these effects are conserved between these hosts, periods of suitable climatic conditions may provide windows of opportunity for cross-species transmission to occur. Serosurveillance studies in human populations in Africa have revealed a much higher prevalence of ebolavirus antibodies than the attack rate reported in previous EVD outbreaks [37,38]. This may suggest that exposure of humans to ebolaviruses or other cross-reactive pathogens was more prevalent than previously thought. In fact, a study of contacts of EVD patients has revealed that some ebolavirus infections can be mild or asymptomatic [39]. Tissue tropism of ebolaviruses has been studied: the viruses were found to target and infect immune cells including monocytes, macrophages and immature dendritic cells and to cause highly pathological immune responses $[40,41]$. Further studies should characterise how previously identified environmental effects on the immune response [33-36] may translate to ebolavirus infection outcomes. Since EVD cases with milder symptoms are more likely to be under-reported, the observed EVD outbreak pattern may in part be attributable to seasonal differences in EVD severity.

In the past, EVD outbreaks were confined to the central African countries and it is essential to understand why EVD has appeared in West Africa. This will have implications on how likely it is that EVD outbreaks will occur in the rest of the world. Climate has been found in our study to be associated with EVD outbreaks and, as discussed in this paper, there are a number of ways in which climate could be associated with the seasonal risk factors of EVD outbreaks. Further studies should investigate the potential impact of climate change on the geographical boundary of the virus and the time period in which EVD is likely to occur.
There are a number of limitations in this study. The initial identification of EVD outbreaks in Africa has mostly been reliant on the clinical manifestation of cases; however, some EVD cases presented with non-specific symptoms that can be easily confused with other diseases that are endemic in Africa [42]. Due to the limited resources and remoteness of some of the rural areas where human-animal contacts are most frequent, some EVD outbreaks might be under-detected. Delayed detection of EVD outbreaks should be expected and we addressed this by using distributed time-lag models. However, it is still difficult to interpret or construct the time structure of the exposure-response relationship since little information on reporting delays is available. The incubation period of EVD may be up to 21 days or more [43], and this has to be taken into account when interpreting time-lagged effects of environmental exposures. The choice of time structure of the exposure-response relationship is based on the model best fitting our data. Given that EVD outbreaks in humans are rather rare, our study may be underpowered to investigate a more sophisticated time structure of the exposure-response relationship and to detect a nonlinear exposure-response relationship. The earliest few human cases are likely to be under-detected and our study may have excluded smaller EVD outbreaks that were unreported. While climatic variation can be a useful predictor, its association with EVD outbreaks may depend on other ecological and environmental factors, as well as on natural host species that vary between geographical areas. Our findings may therefore only apply to areas that share similar characteristics with the outbreak areas included in the analyses. It is most likely that ecological and environmental differences also exist between outbreak areas included the analyses. Our country-specific analyses were unfortunately underpowered, as EVD outbreaks are rare. It is also possible that the association between climate and EVD is specific to ebolavirus species. Our study was only able to provide estimates for Zaire ebolavirus outbreaks since there were fewer outbreaks due to other ebolavirus species.

In order to understand the transmission dynamics of ebolavirus, current efforts in identifying the natural and intermediate hosts of ebolaviruses should be continued and supported. A better understanding of the chain of transmission from the natural reservoir to humans is essential for characterising the epidemiology of ebolavirus infections and directing public health preventive policies. Longitudinal serological and virological surveillance studies will help in identifying the event sequence and interfaces that are important for outbreaks in humans. Our study focused on the onset of EVD outbreaks, as we aimed to investigate environmental factors that are associated with cross-species transmission. To enable factors associated with human-to-human transmission to be investigated, current support to the outbreak countries in case detection and reporting should be continued. 


\section{Conflict of interest}

$B J C$ reports receiving research funding from MedImmune Inc and consults for Crucell NV. The authors report no other potential conflicts of interest.

\section{Authors' contributions}

SN, NEB and BJC have each participated in the conception, design, analysis and writing of the manuscript.

\section{References}

1. Centers for Disease Control and Prevention (CDC). Outbreaks chronology: Ebola hemorrhagic fever. Atlanta, GA: CDC. Updated 26 Mar 2014. [Accessed 28 Mar 2014]. Available from: http://www.cdc.gov/vhf/ebola/resources/outbreak-table.html

2. Peters CJ, LeDuc JW. An introduction to Ebola: the virus and the disease. J Infect Dis. 1999;179 Suppl 1:ix-xvi. http://dx.doi. org/10.1086/514322

3. World Health Organization (WHO) Regional Office for Africa. Ebola virus disease, Liberia (Situation as of 30 March 2014). Brazzaville: WHO Regional Office for Africa. Updated 30 Mar 2014. [Accessed 31 Mar 2014]. Available from: http://www.afro. who.int/en/clusters-a-programmes/dpc/epidemic-a-pandemicalert-and-response/outbreak-news/4072-ebola-haemorrhagicfever-liberia.html

4. Bagcchi S. Ebola haemorrhagic fever in west Africa. Lancet Infect Dis. 2014;14(5):375. http://dx.doi.org/10.1016/ S1473-3099(14)70034-9

5. Baize S, Pannetier D, Oestereich L, Rieger T, Koivogui L, Magassouba N, et al. Emergence of Zaire Ebola virus disease in Guinea - preliminary report. N Engl J Med. 2014 Apr 16. [Epub ahead of print]. http://dx.doi.org/10.1056/NEJMoa1404505

6. Muyembe-Tamfum JJ, Mulangu S, Masumu J, Kayembe JM, Kemp A, Paweska JT. Ebola virus outbreaks in Africa: past and present. Onderstepoort J Vet Res. 2012;79(2):451. http:// dx.doi.org/10.4102/ojvr.v79i2.451

7. Leroy EM, Epelboin A, Mondonge V, Pourrut X, Gonzalez JP, Muyembe-Tamfum JJ, et al. Human Ebola outbreak resulting from direct exposure to fruit bats in Luebo, Democratic Republic of Congo, 2007. Vector Borne Zoonotic Dis. 2009;9(6):723-8. http://dx.doi.org/10.1089/vbz.2008.0167

8. European Centre For Disease Prevention and Control (ECDC) Rapid risk assessment. Outbreak of ebola virus disease in West Africa. Third update, 1 August 2014. ECDC: Stockholm; 2014. Available from: http://ecdc.europa.eu/en/publications/ Publications/ebola-outbreak-west-africa-1-august-2014.pdf

9. Pinzon JE, Wilson JM, Tucker CJ, Arthur R, Jahrling PB, Formenty P. Trigger events: enviroclimatic coupling of Ebola hemorrhagic fever outbreaks. Am J Trop Med Hyg. 2004;71(5):664-74.

10. Bausch DG, Schwarz L. Outbreak of ebola virus disease in Guinea: where ecology meets economy. PLoS Negl Trop Dis. 2014;8(7):e3056. http://dx.doi.org/10.1371/journal. pntd.0003056

11. Harris I, Jones PD, Osborn TJ, Lister DH. Updated highresolution grids of monthly climatic observations - the CRU TS3.10 Dataset. Int J Climatol. 2013;34(3):623-42. Epub 21 May 2013. http://dx.doi.org/10.1002/joc.3711

12. Parish 00, Putnam TW. Equations for the determination of humidity from dewpoint and psychrometric data. Washington, DC: National Aeronautics and Space Administration (NASA); 1977. NASA Technical Note D-8401. Available from: http:// www.nasa.gov/centers/dryden/pdf/87878main_H-937.pdf

13. Gasparrini A, Armstrong B, Kenward MG. Distributed lag nonlinear models. Stat Med. 2010;29(21):2224-34. http://dx.doi. org/10.1002/sim.3940

14. Liang K-Y, Zeger SL. Longitudinal data analysis using generalized linear models. Biometrika. 1986;73(1):13-22. http://dx.doi.org/10.1093/biomet/73.1.13

15. Hardin JW, Hilbe JM. Generalized estimating equations. 2nd ed. Boca Raton, FL: Chapman and Hall/CRC Press; 2012 Available from: http://www.crcnetbase.com/isbn/978-1-4398-8113-2

16. Wittmann TJ, Biek R, Hassanin A, Rouquet P, Reed P, Yaba $P$, et al. Isolates of Zaire ebolavirus from wild apes reveal genetic lineage and recombinants. Proc Natl Acad Sci U S A. 2007;104(43):17123-7. http://dx.doi.org/10.1073/ pnas.0704076104

17. Peterson AT, Bauer JT, Mills JN. Ecologic and geographic distribution of filovirus disease. Emerg Infect Dis. 2004;10(1):40-7. http://dx.doi.org/10.3201/eid1001.030125
18. Johnson BK, Wambui C, Ocheng D, Gichogo A, Oogo S, Libondo $D$, et al. Seasonal variation in antibodies against Ebola virus in Kenyan fever patients. Lancet. 1986;1(8490):116o. http:// dx.doi.org/10.1016/S0140-6736(86)91876-3

19. Busico KM, Marshall KL, Ksiazek TG, Roels TH, Fleerackers Y, Feldmann $\mathrm{H}$, et al. Prevalence of IgG antibodies to Ebola virus in individuals during an Ebola outbreak, Democratic Republic of the Congo, 1995. J Infect Dis. 1999;179 Suppl 1:S102-7. http://dx.doi.org/10.1086/514309

20. Groseth A, Feldmann H, Strong JE. The ecology of Ebola virus. Trends Microbiol. 2007;15(9):408-16. http://dx.doi. org/10.1016/j.tim.2007.08.001

21. Monath TP. Ecology of Marburg and Ebola viruses: speculations and directions for future research. Journal Infect Dis. 1999;179 Suppl 1:S127-38. http://dx.doi.org/10.1086/514281

22. Olival KJ, Islam A, Yu M, Anthony SJ, Epstein JH, Khan SA, et al. Ebola virus antibodies in fruit bats, Bangladesh. Emerg Infect Dis. 2013;19(2):270-3. http://dx.doi.org/10.3201/ eid1902.120524

23. Pourrut X, Delicat A, Rollin PE, Ksiazek TG, Gonzalez JP, Leroy EM. Spatial and temporal patterns of Zaire ebolavirus antibody prevalence in the possible reservoir bat species. J Infect Dis. 2007;196 Suppl 2:S176-83. http://dx.doi.org/10.1086/520541

24. Doran D. Influence of seasonality on activity patterns, feeding behavior, ranging, and grouping patterns in Taï chimpanzees. Int J Primatol. 1997;18(2):183-206. http://dx.doi. org/10.1023/A:1026368518431

25. Bausch DG, Towner JS, Dowell SF, Kaducu F, Lukwiya M, Sanchez A, et al. Assessment of the risk of Ebola virus transmission from bodily fluids and fomites. I Infect Dis. 2007;196 Suppl 2:S142-7. http://dx.doi.org/10.1086/520545

26. Rowe AK, Bertolli J, Khan AS, Mukunu R, Muyembe-Tamfum JJ, Bressler D, et al. Clinical, virologic, and immunologic followup of convalescent Ebola hemorrhagic fever patients and their household contacts, Kikwit, Democratic Republic of the Congo. Commission de Lutte contre les Epidemies a Kikwit. J Infect Dis. 1999;179 Suppl 1:S28-35. http://dx.doi.org/10.1086/514318

27. O'Shea TJ, Cryan PM, Cunningham AA, Fooks AR, Hayman DT, Luis AD, et al. Bat flight and zoonotic viruses. Emerg Infect Dis. 2014;20(5):741-5. http://dx.doi.org/10.3201/eid2005.130539

28. Zhang G, Cowled C, Shi Z, Huang Z, Bishop-Lilly KA, Fang $X$, et al. Comparative analysis of bat genomes provides insight into the evolution of flight and immunity. Science. 2013;339(6118):456-6o. http://dx.doi.org/10.1126/ science.1230835

29. Rouquet P, Froment JM, Bermejo M, Kilbourn A, Karesh W, Reed $P$, et al. Wild animal mortality monitoring and human Ebola outbreaks, Gabon and Republic of Congo, 2001-2003. Emerg Infect Dis. 2005;11(2):283-90. http://dx.doi.org/10.3201/ eid1102.040533

30. Lahm SA, Kombila M, Swanepoel R, Barnes RF. Morbidity and mortality of wild animals in relation to outbreaks of Ebola haemorrhagic fever in Gabon, 1994-2003. Trans R Soc Trop Med Hyg. 2007;101(1):64-78. http://dx.doi.org/10.1016/j. trstmh.2006.07.002

31. Bermejo M, Rodriguez-Teijeiro JD, Illera G, Barroso A, Vilà C, Walsh PD. Ebola outbreak killed 5000 gorillas. Science. 2006;314(5805):1564. http://dx.doi.org/10.1126/ science.1133105

32. Kuhn JH. Ecology of filoviruses: search for reservoirs. In: Calisher $\mathrm{CH}$, editor. Filoviruses: a compendium of 40 years of epidemiological, clinical, and laboratory studies. New York, NY: Springer Vienna; 2008. p. 153-70.

33. Fairchild KD, Viscardi RM, Hester L, Singh IS, Hasday JD. Effects of hypothermia and hyperthermia on cytokine production by cultured human mononuclear phagocytes from adults and newborns. JInterferon Cytokine Res. 2000;20(12):1049-55. http://dx.doi.org/10.1089/107999000750053708

34. Mace TA, Zhong L, Kilpatrick C, Zynda E, Lee CT, Capitano $M$, et al. Differentiation of CD8+ T cells into effector cells is enhanced by physiological range hyperthermia. J Leukoc Biol. 2011;90(5):951-62. http://dx.doi.org/10.1189/jlb.0511229

35. Brenner IK, Castellani JW, Gabaree C, Young AJ, Zamecnik J, Shephard RJ, et al. Immune changes in humans during cold exposure: effects of prior heating and exercise. J Appl Physiol. 1999;87(2):699-710.

36. Nelson RJ, Demas GE, Klein SL, Kriegsfeld LK, Bronson F. Seasonal patterns of stress, immune function, and disease. New York, NY: Cambridge University Press; 2002. http://dx.doi. org/10.1017/CB09780511546341

37. Gonzalez JP, Josse R, Johnson ED, Merlin M, Georges AJ, Abandja J, et al. Antibody prevalence against haemorrhagic fever viruses in randomized representative Central African populations. Res Virol. 1989;140(4):319-31. http://dx.doi. org/10.1016/Sog23-2516(89)80112-8 
38. Becquart P, Wauquier N, Mahlakoiv T, Nkoghe D, Padilla C, Souris M, et al. High prevalence of both humoral and cellular immunity to Zaire ebolavirus among rural populations in Gabon. PloS One. 2010;5(2):e9126. http://dx.doi.org/10.1371/ journal.pone.0009126

39. Leroy EM, Baize S, Volchkov VE, Fisher-Hoch SP, GeorgesCourbot MC, Lansoud-Soukate J, et al. Human asymptomatic Ebola infection and strong inflammatory response. Lancet. 2000;355(9222):2210-5. http://dx.doi.org/10.1016/ S0140-6736(00)02405-3

40. Zampieri CA, Sullivan NJ, Nabel G). Immunopathology of highly virulent pathogens: insights from Ebola virus. Nat Immunol. 2007;8(11):1159-64. http://dx.doi.org/10.1038/ni1519

41. Wong G, Kobinger GP, Qiu X. Characterization of host immune responses in Ebola virus infections. Expert Rev Clin Immunol. 2014;10(6):781-90. http://dx.doi.org/10.1586/174466 6X.2014.908705

42. Centers for Disease Control and Prevention (CDC). Signs and symptoms. Ebola hemorrhagic fever. Atlanta, GA: CDC. [Accessed 3 Aug 2014]. Available from: http://www.cdc.gov/ vhf/ebola/symptoms/

43. Eichner M, Dowell SF, Firese N. Incubation period of ebola hemorrhagic virus subtype Zaire. Osong Public Health Res Perspect. 2011;2(1):3-7. http://dx.doi.org/10.1016/j. phrp.2011.04.001 